Gut, 1976, 17, 709-713

\title{
Idiopathic cholestasis of pregnancy in a large kindred
}

\author{
HUMBERTO REYES, ${ }^{1}$ J. RIBALTA, AND M. GONZÁLEZ-CERÓN
}

From the Departments of Medicine and Experimental Medicine, University of Chile (Eastern Campus) and the Hospital del Salvador, Santiago, Chile

SUMMARY A past history of idiopathic cholestasis of pregnancy (ICP) was detected in 10 out of the 32 multiparous women in the last two generations of a large kindred. The affected women are distributed in five family units, sharing Chilean-born great-grandparents. The connection between the ICP-affected women and the common trunk is given both by male and female parents. Five cases are concentrated in one family unit, where the mother and all her daughters have been affected by the disease. The role of genetic factors in the pathogenesis of ICP is supported by this study. It is proposed that the disease may be transmitted as a predisposing trait by individuals of either sex and that non-genetic factors may influence its expressivity. A reliable test to identify all the genetic carriers seems indispensable to define the pattern of inheritance in this disease.

A well-defined form of intrahepatic cholestasis has been widely recognized as a rare complication of pregnancy (Ahlfeld, 1883, cited by Ikonen, 1964; Svanborg, 1954; Thorling, 1955; Arfwedson, 1956; Haemmerli, 1966). Although it is of unknown aetiology, some epidemiological characteristics have suggested that genetic factors play a role in its pathogenesis:

1. The incidence of the disease is strikingly higher in Chile and some Scandinavian countries than in most other European and American countries (Svanborg and Ohlsson, 1959; Ikonen, 1964; Osorio, 1964; Reyes et al., 1968; Adlercreutz and Tenhunen, 1970; Forkman et al., cited by Rannevik et al., 1972; Furhoff, 1974);

2. In 1968, Reyes and his colleagues suggested that a higher incidence of the disease could be found in women of Araucanian Indian descent, as compared with Chilean women without overt Indian admixture. This observation has been confirmed in a more recent study (Reyes et al., to be published);

3. In a large group of Swedish women with a past history of jaundice due to oral contraceptives and in their mothers and sisters, Dalén and Westerholm (1974) found a higher incidence of cholestasis of

\footnotetext{
${ }^{1}$ Address for reprints requests: Dr $H$. Reyes, Facultad de Medicina, Universidad de Chile, Sede Oriente, Casilla 16038, Santiago 9, Chile.

Received for publication 19 May 1976
}

pregnancy than in a carefully matched control group;

4. A small number of families with a few affected members has been reported (Svanborg and Ohlsson, 1959; Perreau and Rouchy, 1961; Cahill, 1962; Fast and Roulston, 1964; Ikonen, 1964; Holzbach and Sanders, 1965; Haemmerli, 1966; Furhoff and Hellström, 1973; Furhoff, 1974).

However, these observations are insufficient to postulate a simple form of hereditary transmission for this disease. It seems important to gather more examples of case distribution and aggregation in families with overtly affected members, at least to reinforce the hypothesis that genetic factors are influential in the pathogenesis of idiopathic cholestasis of pregnancy.

In this paper we report a marked familial aggregation of cholestasis of pregnancy in a kindred with 123 individuals of both sexes, distributed in three collateral branches and in four generations. Because an epidemiological connection between cholestasis of pregnancy and calculous biliary tract disease has been proposed (Furhoff, 1974; Furhoff and Hellström, 1974; Engström et al., cited by Dalén and! Westerholm, 1974), a past history of cholelithiasis was simultaneously sought in this study.

\section{Methods}

A 25 year old woman, seen in consultation at the Department of Obstetrics during a typical episode 
of recurrent cholestatic jaundice of pregnancy, became the index case. As the patient reported that her mother and three sisters had suffered similar symptoms while pregnant, a pedigree was traced and its members were personally interviewed and examined by the authors.

In parous women, the existence or absence of a past history of idiopathic intrahepatic cholestasis of pregnancy (ICP) was recorded. In all individuals of both sexes, present age, a past history of cholecystectomy or abnormal cholecystograms, and the age at which they were performed were also registered.

The retrospective diagnosis of ICP was based on the following criteria:

1. A past history of generalized pruritus, with or without jaundice, appearing during pregnancy, persisting until delivery, and disappearing a few hours or days post-partum.

2. A.bsence of biliary colicky pain during the itching period in pregnancy.

3. Absence of jaundice or generalized pruritus in non-pregnant periods.

4. Absence of a chronic liver disease.

Cases with a past history of well-defined itching without jaundice, were classified as pruritus gravidarum. Recurrence of pruritus in several pregnancies with or without jaundice, was considered a reinforcement of the diagnosis but not an essential requisite in multiparous women.

A retrospective diagnosis of cholestatic jaundice of pregnancy was made when a woman could remember a slight but evident jaundice during a pregnancy, accompanied by dark urine and pruritus, with the aforementioned characteristics. In most cases, mildly increased total and direct reacting serum bilirubin during pregnancies could be confirmed in the patient's medical records.

According to current diagnostic criteria (Sjövall and Sjövall, 1966; Haemmerli and Wyss, 1967; Kater et al., 1967; Kater and Mistilis, 1967; Ylöstalo, 1970; Furhoff and Hellström, 1973; Tikkanen and Adlercreutz, 1973; Adlercreutz et al., 1974; Furhoff and Hellström, 1974; Johnson et al., 1975; Samsioe et al., 1975), both cholestatic jaundice of pregnancy and pruritus gravidarum were included in this study under the name of 'idiopathic cholestasis of pregnancy' (ICP). In all cases, generalized pruritus was the initial and most prominent symptom appearing no later than four weeks before delivery.

The diagnosis of cholelithiasis was made only in cases with gallstones proven before the survey either by cholecystectomy or an oral cholecystogram. No prospective cholecystograms were performed during this study.

\section{Results}

Starting from the proband, a pedigree could be traced up to four great-grandparents along the maternal line. One of the great-grandfathers was born in Italy. The other three great-grandparents were born in Chile and belonged to families founded several generations ago. We assume that they have some Araucanian Indian admixture in their apparently pure Spanish descent.

Three family branches originated from these four ancestors. The survey included direct interview of $64 \%$ of the living members in both sexes. Additional information about several unavailable living or dead members, concerning their place in the pedigree and a past history of cholecystectomy, could be obtained from close relatives. For women at childbearing age, direct interview was obtained in over $90 \%$. The proportion of unavailable cases and of cases with indirectly obtained data was roughly similar in the three branches of the pedigree.

Among 32 parous women in the last two generations, a past history of ICP was detected in 10 $(31 \cdot 2 \%)$. The Figure illustrates the two branches of the pedigree where ICP-affected women were found. Both branches share only Chilean-born great-grandparents and are connected in the second generation through a female (see Figure, case FII-2). Most affected women were concentrated in the pedigree branch to which the proband belongs. The mother of the proposita (FII-10) had pruritus gravidarum in each of her 13 pregnancies and all her daughters (FIV-18, 19, 20, 21) had ICP, manifested in seven of their nine pregnancies. This is the only family unit where the disease was found in two generations.

Cases FIII-25 and FIV-1 are affected women, connected to the pedigree through their fathers. Neither their mothers nor their mothers' blood relatives have had ICP.

To the left of the branch where the proband belongs, extends a third branch (not shown in the Figure). Both branches share the Italian-born greatgrandfather and are connected in the second generation through a male (FII-1). In this third branch, ICP was not detected in any of the 29 pregnancies in the eight parous women of the last two generations, nor in 16 pregnancies in the wives of three male members.

Five women with a past history of ICP have undergone cholecystectomy, but gallstones had also been proven in 11 women apparently without ICP, and in two male members, distributed in the three branches of the pedigree.

Two cases of alcoholic liver cirrhosis were found in the whole kindred, both being males. No signs of 


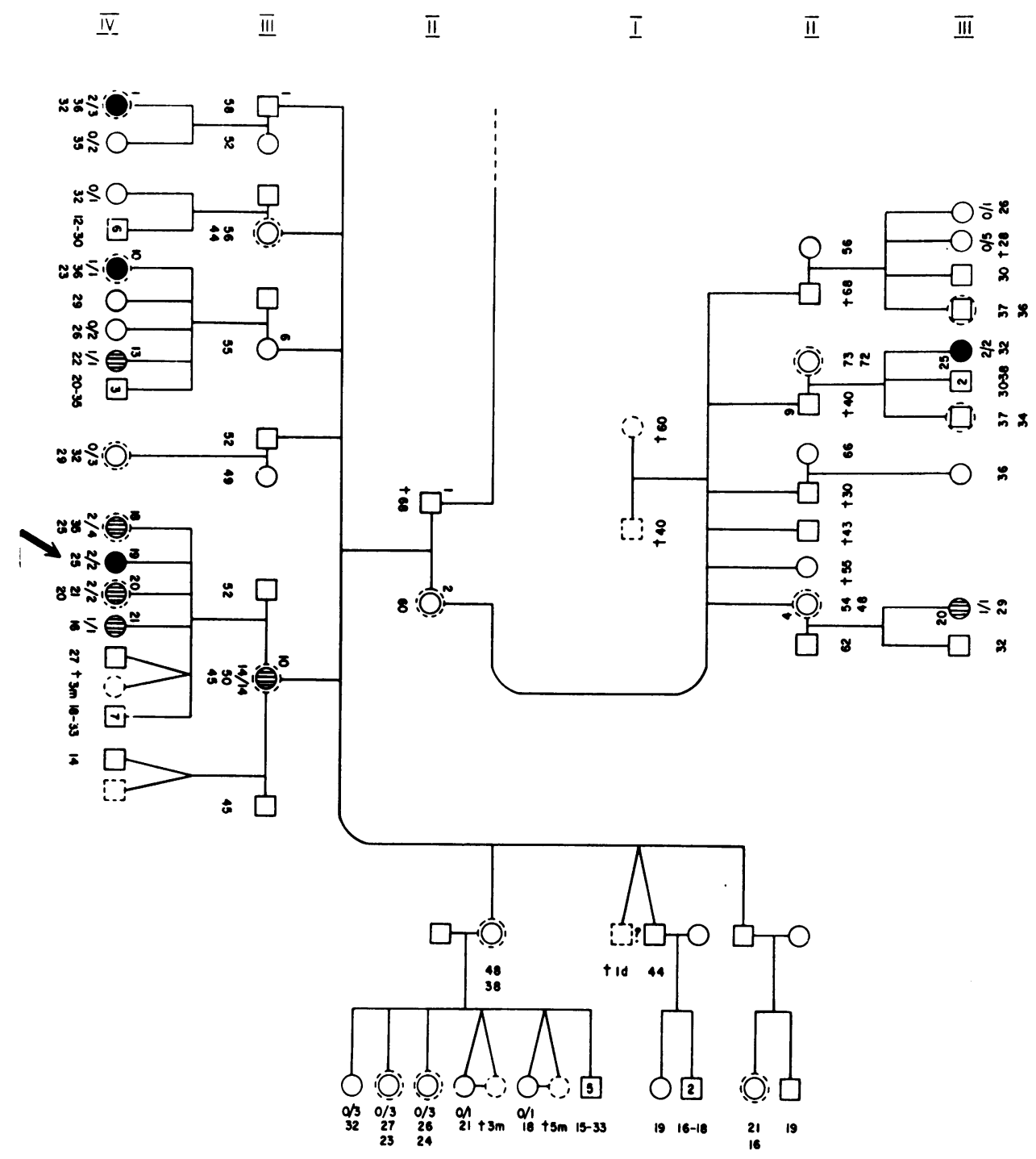

Figure Pedigree, gestational, and clinical data of a kindred with several members affected by idiopathic cholestasis of pregnancy (ICP). Only the two branches sharing Chilean-born great-grandparents and ICP-affected individuals are shown.

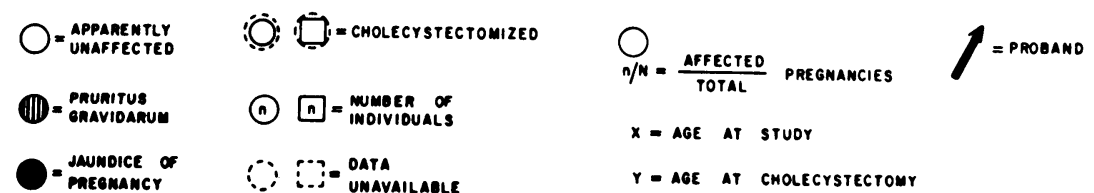


constitutional hyperbilirubinaemias or other types of familial recurrent cholestasis were discovered. Liver function tests, including bromsulphalein clearances, were normal in three women with a past history of ICP, examined several months or years after their last pregnancy.

\section{Discussion}

The marked familial aggregation of ICP observed in this study and the finding of two generations heavily affected in one family is compatible with the participation of genetic factors, following a Mendelian type of inheritance. The incidence of ICP detected among 32 related parous women in the last two generations is significantly higher than the figure obtained in a recent population survey (Reyes et al., to be published) in which a large sample of Chilean women at childbearing age was examined $(31.2 \%$ versus $15.7 \%$, respectively, $\mathrm{P}<0.01)$.

Food intake, eating habits, and nutritional status in members of the branches that share the Italianborn great-grandfather appeared similar to most middle-class people in Santiago, while ICP-affected cases were found in only one of these branches. In contrast, a different standard of living was apparent in members of the branch sharing only Chilean ancestors, where other ICP-affected women were found. This observation reduces the potential influence of environmental factors and suggests that a genetic predisposition to ICP was inherited by the ICP-affected women from the Chilean ancestors depicted in the Figure. In the branch where the proband belongs, transmission to the third generation must have occurred through FII-2 and not through her husband.

In this paper and in a previous study (Reyes et al., 1974) we have observed families with several affected women whose mothers never expressed the disease in their own pregnancies. We may presume that these mothers acted only as carriers, transmitting the trait to their descendants.

In two family units in this pedigree, the connection between the affected women and the common trunk was given by males, suggesting that the genetic predisposition may be transmitted by individuals of either sex.

As shown in the Figure, the distribution of cases that have undergone cholecystectomy does not strictly coincide with the familial case aggregation of ICP. Obviously, asymptomatic gallstones might have been discovered through prospective cholecystograms of all the adult members in the whole kindred, but this was not feasible. The apparently high rate of cases that had undergone cholecystectomy ( $20 \%$ of 120 individuals over 20 years of age) may only be reflecting the high incidence of cholelithiasis in the Chilean population, previously demonstrated by others (Marinovic et al., 1972; Medina et al., 1972). The relationship between ICP and cholelithiasis is certainly a subject that deserves further study, mainly when both diseases show a simultaneously high incidence in some populations, as in Chile, but apparently not in others, as the Pima and Chippewa Indians in the U.S.A.

Most previous reports of ICP-affected families refer to only two or three women as having the disease and very few of them describe the size of the family. Pedigree studies tracing a presumptive genetic transmission of the disease have not been published.

Although the present study provides further evidences for a genetic predisposition to ICP, a classic segregation analysis for the inheritance of this disease is hindered by characteristics of its expressivity:

1. It is limited by sex and gestation. The existence of male carriers cannot yet bedemonstrated or denied. Besides, it is impossible to score nulliparous women as affected or unaffected.

2. It is variable, both in duration and intensity of the cholestatic episodes. This makes difficult the retrospective diagnosis in elder women whose last pregnancy occurred several years before a survey is performed.

3. It is not constant for every pregnancy in an affected woman. A woman with low parity may be wrongly considered as 'non-affected', while the disease may become apparent in future pregnancies.

Most authors consider that ICP represents an abnormal reaction of the maternal liver to endogenous oestrogens or some metabolites. A genetic predisposition seems well documented by the present and other studies. However, the clinical variability of this disease opens the question of the coexistence of non-genetic factors triggering and modifying its expressivity. A method allowing the discovery of every genetic carrier for the disease, in both sexes, would be extremely helpful in solving these problems.

We are grateful to Dr Ricardo Cruz-Coke for his stimulating advice, and to our colleagues on the Department of Obstetrics, Hospital del Salvador, for their permission to investigate patients admitted under their care. We would also like to thank all the members of the kindred in question who have given us information and help.

This study was supported by a grant from the Servicio de Desarrollo Científico, Universidad de Chile. 


\section{References}

Adlercreutz, H. and Tenhunen, R. (1970). Some aspects of the interaction between natural and synthetic female sex hormones and the liver. American Journal of Medicine, 49, 630-648.

Adlercreutz, H., Tikkanen, M. J., Wichmann, K., Svanborg, A., and Anberg, A. (1974). Recurrent jaundice in pregnancy. 4. Quantitative determination of urinary and biliary estrogens, including studies in Pruritus Gravidarum. Journal of Clinical Endocrinology and Metabolism, 38, 51-57.

Arfwedson, H. (1956). General pruritus in pregnancy: symptom of liver dysfunction. Obstetrics and Gynecology, 7, 274-276.

Cahill, K. M. (1962). Hepatitis in pregnancy. Surgery, Gynecology and Obstetrics, 114, 545-552.

Dalén, E., and Westerholm, B. (1974). Occurrence of hepatic impairment in women jaundiced by oral contraceptives and in their mothers and sisters. Acta Medica Scandinavica, 195, 459-463.

Fast, B. B., and Roulston, T. M. (1964). Idiopathic jaundice of pregnancy. American Journal of Obstetrics and Gynecology, 88, 314-321.

Furhoff, A. K. (1974). Itching in pregnancy: a 15-year follow-up study. Acta Medica Scandinavica, 196, 403-410.

Furhoff, A. K., and Hellström, K. (1973). Jaundice in pregnancy: a follow-up study of the series of women originally reported by $\mathrm{L}$. Thorling. I. The pregnancies. Acta Medica Scandinavica, 193, 259-266.

Furhoff, A. K., and Hellström, K. (1974). Jaundice in pregnancy: a follow-up study of the series of women originally reported by L. Thorling. II. Present health of the women. Acta Medica Scandinavica, 196, 181-189.

Haemmerli, U. P. (1966). Jaundice during pregnancy, with special emphasis on recurrent jaundice during pregnancy and its differential diagnosis. Acta Medica Scandinavica, suppl. 444.

Haemmerli, U. P., and Wyss, H. I. (1967). Recurrent intrahepatic cholestasis of pregnancy: report of six cases, and review of the literature. Medicine (Baltimore), 46, 299-321.

Holzbach, R. T., and Sanders, J. H. (1965). Recurrent intrahepatic cholestasis of pregnancy: observations on pathogenesis. Journal of the American Medical Association, 193, 542-544.

Ikonen, E. (1964). Jaundice in late pregnancy. Acta Obstetrica et Gynecologica Scandinavica, 43, suppl. 5.

Johnson, P., Samsioe, G., and Gustafson, A. (1975). Studies in cholestasis of pregnancy. I. Clinical aspects and liver function tests. Acta Obstetrica et Gynecologica Scandinavica, 54, 77-84.

Kater, R. M. H., Harrison, D D , and Mistilis, S. P. (1967). Alterations in sulfobromophthalein sodium removal from blood in patients with pruritus of pregnancy. Gastro- enterology, 53, 941-946.

Kater, R. M. H., and Mistilis, S. P. (1967). Obstetric cholestasis and pruritus of pregnancy. Medical Journal of Australia, 1, 638-640.

Marinovic, I., Guerra, C., and Larach, G. (1972). Incidencia de litiasis en material de autopsias y análisis de composición de los cálculos. Revista Médica de Chile, 100, 1320-1327.

Medina, E., Kaempffer, A. M., Croizet, V. A., Yrarrázaval, M., and Toporowicz, M. (1972). Epidemiología de las colecistopatías en Chile. II. Factores de importancia en estudios de autopsia. Revista Médica de Chile, 100, 1382-1389.

Osorio, R. (1964). Colestasis intrahepática del embarazo. Revista Chilena de Obstetricia y Ginecología, 29, 51-64.

Perreau, P., and Rouchy, R. (1961). Ictère cholostatique récidivant de la grossesse. Gynécologie et Obstétrique, 60, 161-179.

Rannevik, G., Jeppsson, S., and Kullander, S. (1972). Effect of oral contraceptives on the liver in women with recurrent cholestasis (hepatosis) during previous pregnancies. Journal of Obstetrics and Gynecology of the British Commonwealth, 79, 1128-1136.

Reyes, H., Radrigán, M. E., Schramm, G., and Katz, R. (1968). Frecuencia de ictericia y prurito idiopático del embarazo en mujeres chilenas. Revista Médica de Chile, 96, 409-414.

Reyes, H., Ribalta, J., Gonzalez, M. C., and Katz, R. (1974). Colestasia idiopática del embarazo en 2 familias chilenas: una hipótesis sobre la patogenia de la enfermedad. Revista Médica de Chile, 102, 913-917.

Samsioe, G., Johnson, P., and Gustafson, A. (1975). Aspects of the pathogenesis of cholestasis of pregnancy with reference to the serum lipid abnormalities. Scandinavian Journal of Gastroenterology, 10, 1-4.

Sjövall, K., and Sjövall, J. (1966). Serum bile acid levels in pregnancy with pruritus (Bile acids and steroids 158). Clinica Chimica Acta, 13, 207-211.

Svanborg, A. (1954). A study of recurrent jaundice in pregnancy. Acta Obstetrica et Gynecologica Scandinavica, 33, 434-444.

Svanborg, A., and Ohlsson, S. (1959). Recurrent jaundice of pregnancy: a clinical study of twenty-two cases. American Journal of Medicine, 27, 40-49.

Thorling, L. (1955). Jaundice in pregnancy: a clinical study. Acta Medica Scandinavica, 151, suppl. 302.

Tikkanen, M. J., and Adlercreutz, H. (1973). Recurrent jaundice in pregnancy. 3. Quantitative determination of urinary estriol conjugates, including studies in pruritus gravidarum. American Journal of Medicine, 54, 600-604.

Ylöstalo, P. (1970). Liver function in hepatosis of pregnancy and pre-eclampsia, with special reference to modified Bromsulphthalein tests. Acta Obstetrica et Gynecologica Scandinavica, 49, suppl. 4. 